\title{
Acute respiratory illness as a trigger for detecting chronic bronchitis in adults at risk of COPD: a primary care survey
}

\author{
*Nicolas Rochea , Jacques Gaillat ${ }^{b}$, Michel Garrec, Jean-Pierre Meunier ${ }^{d}$, \\ Nicolas Lemaire ${ }^{d}$, Hakim Bendjenana ${ }^{e}$ \\ a Service de Pneumologie et Réanimation, Hôpital Hôtel-Dieu, Université Paris-Descartes, AP-HP, Paris, France \\ b Service des Maladies Infectieuses Centre Hospitalier d'Annecy, Annecy Cedex, France \\ ' Service de Médecine Interne et des Maladies Infectieuses, CHU de la Cavale Blanche, Brest Cedex, France \\ 'AXONAL, Nanterre Cedex, France \\ e Laboratoire ABBOTT France, Cedex, France
}

Received 27th October 2009; resubmitted 25th January 2010; revised 8th March 2010; accepted 2nd May 2010; online 9th September 2010

\begin{abstract}
Aim: To evaluate the impact of chronic bronchitis in patients identified among subjects at risk of chronic obstructive pulmonary disease (COPD) but currently free from any known chronic respiratory disorder, visiting a general practitioner for an acute respiratory episode.

Method: A multicentre, cross-sectional survey carried out in primary care.

Results: Primary care practitioners ( $n=772$ ) examined 14,030 patients with acute cough (male: $56.9 \%$, age $50.6 \pm 16.5$ years). Of these, 3,615 were at risk of COPD ( $>40$ years and tobacco use $>10$ pack-years) and constituted the study population: $79.8 \%$ reported current symptoms of chronic bronchitis. Compared to patients without chronic bronchitis, they were older, more frequently exposed to occupational pollutants or to passive smoking, had more tobacco use $(p<0.001)$, reported dyspnoea $\geq$ Grade 2 more frequently, and had poorer quality of life as assessed by the EuroQOL-5D questionnaire.

Conclusions: In this survey, previously unrecognised chronic bronchitis was diagnosed in a high proportion of at-risk patients with acute respiratory episodes. Chronic bronchitis was associated with significantly poorer health status. Acute respiratory illness could be an appropriate opportunity for screening those patients at risk of COPD with lung function testing

(C) 2010 Primary Care Respiratory Society UK. All rights reserved.

N Roche et al. Prim Care Resp J 2010; 19(4): 371-377

doi:10.4104/pcrj.2010.00042
\end{abstract}

Keywords COPD, exacerbation, hospitalisation, telephone support, service development

\section{Introduction}

Chronic obstructive pulmonary disease (COPD) is a leading cause of world-wide mortality and disability. Its long-lasting course is characterised by irreversible decline in the forced expiratory volume in one second $\left(\mathrm{FEV}_{1}\right)$, increasing dyspnoea, progressive deterioration of health status, and acute exacerbations leading to an increased use of health services. . $^{2-4}$

A diagnosis of airflow obstruction may increase the success rate of smoking cessation attempts - thereby slowing disease progression and increasing life expectancy - and may allow early initiation of appropriate treatments, thereby reducing disability. ${ }^{2-6}$ However, a definitive diagnosis is required. In France, as in other industrialised countries, spirometry data in the population suggest a prevalence of COPD (as defined by an $\mathrm{FEV}_{1} / \mathrm{FVC}$ ratio $<0.7 \%$ ) ranging from $5 \%-15 \%$ in adults. ${ }^{7.8}$ The prevalence of COPD varies markedly depending on the age group studied, making it difficult to compare populations of different age ranges. However, currently available data suggest that the prevalence reaches more than $20 \%$ in current or former smokers over the age of 40 and even $50 \%$ in persistent smokers over the age of $65.9,10$ Most often, the diagnosis is established in subjects who have been smokers for several decades, after a long course of structural and functional changes in the lungs. Consequently, the 10-year survival rate following diagnosis is

\footnotetext{
* Corresponding author: Professor Nicolas Roche, Service de Pneumologie et Réanimation, Hôpital Hôtel-Dieu, AP-HP, Université Paris Descartes, 1 Place du Parvis Notre Dame, 75181 Paris, France. Tel: +33 142348480 Fax: +33 142348448 E-mail: nicolas.roche@htd.aphp.fr
} 
rather low (about 50\%), with more than a third of patients dying due to respiratory failure. ${ }^{11,12}$ In a recent survey in French prevention centres, chronic airflow obstruction was found in $7.5 \%$ of subjects aged 45 years or more. ${ }^{13}$ In $93.9 \%$ of these subjects, no respiratory disease had been diagnosed previously. Despite the predominantly mild to moderate severity of airflow obstruction, it was associated with an impaired health status and work loss. ${ }^{13}$

Under- or late diagnosis is a consequence of the insidious development of COPD: patients tend to adapt to their condition and under-estimate symptoms, thus making early detection difficult. 14,15 To combat this, standardised questionnaires have been developed to help case-finding. ${ }^{16}$ In parallel, the cost-effectiveness of early detection by systematic spirometry in asymptomatic smokers is still debated. ${ }^{17}$

As acute exacerbations represent major events in the natural history of COPD and as they usually prompt patients to seek medical advice, they may be an opportunity to diagnose the disease. A first step could be to identify patients with chronic bronchitis $(C B)$, who are at increased risk of developing COPD, ${ }^{18,19}$ even if chronic bronchitis itself is not included in the latest GOLD classification..$^{20}$ It would also be useful to determine the impact of the respiratory disease in these patients: demonstration of a poorer health status would substantiate the use of chronic bronchitis for case-finding, and increase the awareness of COPD in primary care and the motivation of physicians towards early detection of this disease.

Thus, the objectives of the present study were to assess:

(i) the health status of patients with (previously undiagnosed) chronic bronchitis (CB), compared to that of patients without chronic bronchitis - i.e. to determine whether subjects with chronic bronchitis identified whilst visiting a general practitioner (GP) for an acute respiratory episode already have impaired health status despite being previously undiagnosed.

(ii) the proportion of subjects with chronic bronchitis among at-risk individuals (age $>40$ years, smoking $>10$ packyears) identified when visiting a GP with an apparent clinical presentation of acute bronchitis and no known underlying chronic respiratory disease.

\section{Material and methods}

This French multicentre observational cross-sectional survey was conducted during 2006-2007 in primary care practice. The study protocol was approved by the National Council of the French Medical Association, the French Consultative Committee on Data Processing in Biomedical Research and the French National Data Protection Committee. Informed consent was obtained from all patients.
Figure 1. Studied populations and subgroups.

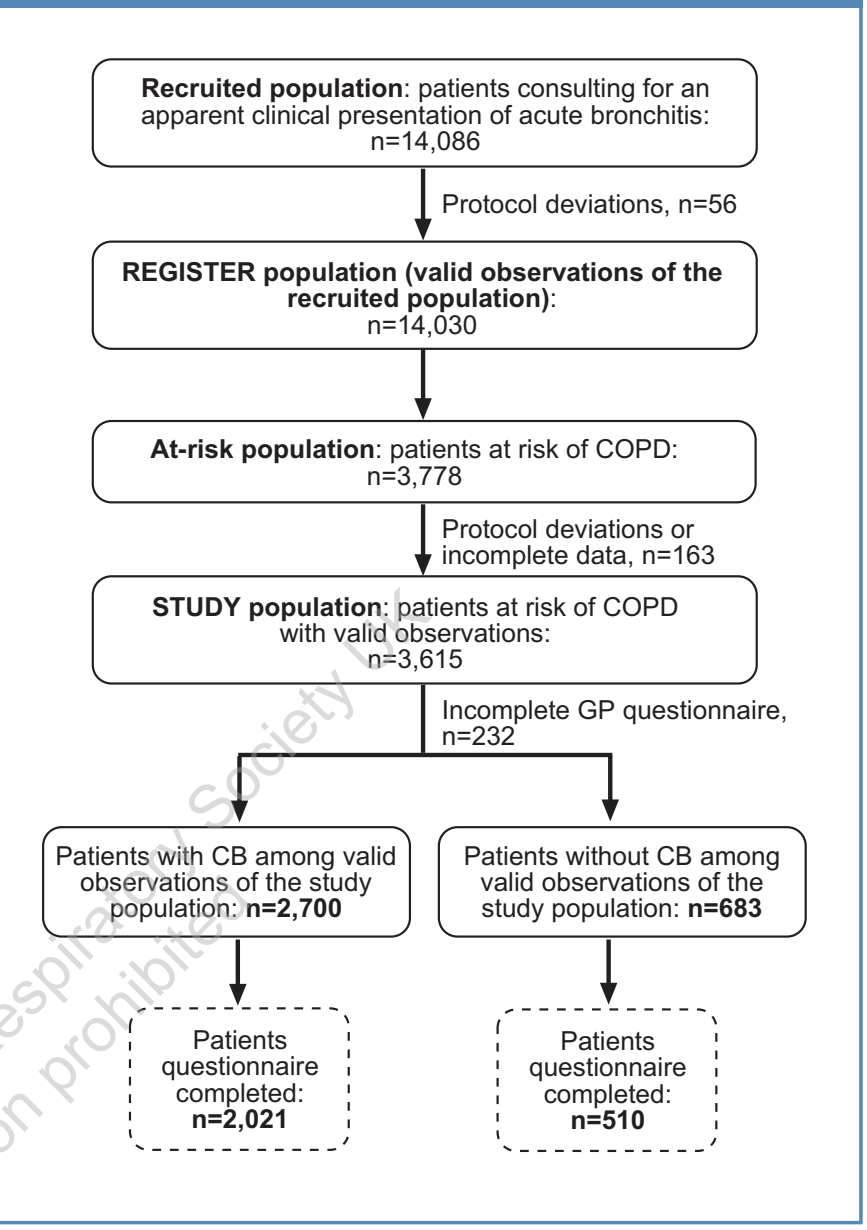

\section{Study populations (see Figure 1)}

Nine hundred GPs located throughout mainland France were asked to participate. Each had to include the first 20 consecutive adult patients (age $>18$ years) with a clinical presentation of acute bronchitis (the recruited population) - i.e. with acute $(<1$ week) sudden cough, with or without expectoration, retrosternal pain or fever, whose clinical state did not justify hospitalisation. Valid observations of the recruited population constituted the "register population". Amongst these patients, each GP had to select the first five consecutive patients considered to be at risk of COPD - i.e. aged over 40 years, with a smoking history $>10$ pack-years (the at-risk population). Valid observations of the at-risk population constituted the "study population".

\section{Data collection}

For the total population, collected data were age, gender, tobacco use, and the presence/absence of known chronic respiratory disease or lung function testing [LFT] within the past two years.

For the at-risk population, GPs had to record information related to chronic respiratory symptoms (cough, expectoration, chronic shortness of breath), tobacco use, previous episodes of 
acute bronchitis and treatment prescriptions. Patients had to report information related to usual symptoms (cough, expectoration, shortness of breath), tobacco use, occupational exposures and previous episodes of acute bronchitis on a selfadministered questionnaire (derived from the European Respiratory Community Health Survey questionnaire). ${ }^{21}$ Perceived health status and global quality of life [QoL] were assessed by the EuroQOL-5D questionnaire. ${ }^{22}$ Chronic bronchitis was defined as chronic productive cough for at least three months per year for at least two consecutive years, as assessed by GP questionnaires. The same definition was applied for patient-recorded data. In patients with chronic bronchitis, the acute respiratory episode at the origin of the visit was subsequently named "acute exacerbation of chronic bronchitis" (AECB).

\section{Statistical analyses}

Considering an expected prevalence of chronic bronchitis of at least $20 \%$ in current or former smokers over the age of 40 years, expecting up to $15 \%$ of non-valuable files and requiring a precision of $2 \%$ for prevalence estimation, 4,500 patients were to be included in the study population to obtain 3,825 valid observations in the study population. This calculation took account of the clustered nature of the sample. The number of clusters (i.e. the number of participating physicians) and of statistical units (i.e. subjects) were calculated to ensure reliable variance estimation and to minimise the risk of sampling errors, knowing that there was only one stage of clustering. Considering a proportion of atrisk subjects of at least $1 / 3$ of the total population, a sample of 13,500 individuals had to be recruited in that population.

All analyses were restricted to valid observations (no protocol deviation) with exploitable questionnaires. In the register population, the study evaluated the proportion of individuals at risk of COPD (> 40 years, tobacco use $>10$ pack-years, without known chronic respiratory disease) and the proportion of patients with chronic bronchitis. In the study population, patients characteristics were described according to the presence or absence of underlying newly diagnosed chronic bronchitis. The statistical tests used for these univariate analysis according to the nature of the analysed variables were the Student's t-test with Sattherwaite's correction if variances were not equal, ShapiroWilk test, Chi-squared or Fischer's exact test and WilcoxonMann-Whitney test. Risk factors which best predicted the presence of chronic bronchitis in the at-risk population were determined using multivariate logistic regression analysis: the most discriminating parameters on univariate analyses $(p<0.2)$ were included in a stepwise procedure to build the best regression model and Odds ratio were calculated.

All tests were two-sided with a significance threshold of $5 \%$. The statistical analyses were carried out using SAS ${ }^{\circledR}$ software, version 8.2, SAS ${ }^{\circledR}$ Institute, NC, Cary, USA.

\section{Results}

\section{Studied populations}

Seven hundred and seventy-two GPs located throughout mainland France actively participated in the survey and recruited 14,086 patients with a primary diagnosis of acute bronchitis (Figure 1). Valid observations were available for 14,030 of them (the "register population": age $50.6 \pm 16.5$ years; male gender: $56.9 \%$; smokers or ex-smokers $\geq 10$ packyears: $54.4 \%$ ). A known underlying respiratory disease was reported by $24 \%(n=3,320)$. Among the remaining subjects, 3,778 ( $27 \%$ of the register population) were at risk of COPD (>40 years old, >10 pack-years). Of these, 3,615 (95.7\%) observations were valid (i.e. no protocol deviation) and represented the study population. The GP questionnaire was completed in 3,383 cases (93.6\%). In that population, the investigators identified underlying chronic bronchitis in $79.8 \%$ of cases $(n=2,700,95 \% \mathrm{Cl}: 78.5-81.2 \%)$

\section{Characteristics of patients with chronic bronchitis in} the study population

The demographic characteristics and respiratory risk factors of patients in the study population, according to the presence or absence of chronic bronchitis, are presented in Table 1. Patients with chronic bronchitis had been or were more frequently exposed to occupational pollutants ( $p<0.001$ ).

Patients with chronic bronchitis suffered from higher degrees of dyspnoea (Figure 2).

Table 1. Cohort population (patients at risk of COPD) demographic characteristics and respiratory risk factors according to the presence/absence of $\mathrm{CB}$.

\begin{tabular}{|c|c|c|c|}
\hline & $\begin{array}{l}\text { with CB } \\
n=2,700\end{array}$ & $\begin{array}{l}\text { without CB } \\
\qquad n=683\end{array}$ & $p$ value \\
\hline \multicolumn{4}{|l|}{ Gender \% (n) } \\
\hline Male & $68.8 \%(1,855)$ & $67.0 \%(457)$ & \multirow[t]{2}{*}{0.367} \\
\hline Female & $31.2 \%(841)$ & $33.0 \%(225)$ & \\
\hline Age (years) & $57.0 \pm 10.3$ & $53.5 \pm 10.2$ & $<0.001$ \\
\hline$[40-65]$ years $\%(n)$ & $78.9 \%(2,129)$ & $85.5 \%(584)$ & $<0.001$ \\
\hline$>65$ years $\%(n)$ & $21.1 \%(571)$ & $14.5 \%(99)$ & \\
\hline BMI $\left(\mathrm{kg} / \mathrm{m}^{2}\right)$ & $26.3 \pm 4.8$ & $25.4 \pm 4.4$ & $<0.001$ \\
\hline \multicolumn{4}{|l|}{ Smoking status } \\
\hline Current smokers \% (n) & $42.8 \%(1,144)$ & $49.0 \%$ (333) & \multirow[t]{2}{*}{0.003} \\
\hline Former smokers \% (n) & $57.2 \%(1,530)$ & $51.0 \%(346)$ & \\
\hline $\begin{array}{l}\text { Age the patient stopped } \\
\text { smoking (years) }\end{array}$ & $52.8 \pm 10.2$ & $47.2 \pm 9.9$ & $<0.001$ \\
\hline $\begin{array}{l}\text { Age the patient started } \\
\text { to smoke (years) }\end{array}$ & $18.7 \pm 4.2$ & $19.2 \pm 4.0$ & 0.002 \\
\hline Smoking duration (years) & $32.8 \pm 11.2$ & $27.9 \pm 10.7$ & $<0.001$ \\
\hline \multicolumn{4}{|c|}{ Patients exposed to other people tobacco smoke $\geq 2$ hours/day } \\
\hline Patients quest. \% $(n)$ & $63.7 \%(1,280)$ & $52.6 \%(266)$ & $<0.001$ \\
\hline \multicolumn{4}{|c|}{ Patients exposed to occupational and environmental pollutants } \\
\hline Patients quest. \% (n) & $43.8 \%(879)$ & $31.0 \%(157)$ & $<0.001$ \\
\hline
\end{tabular}




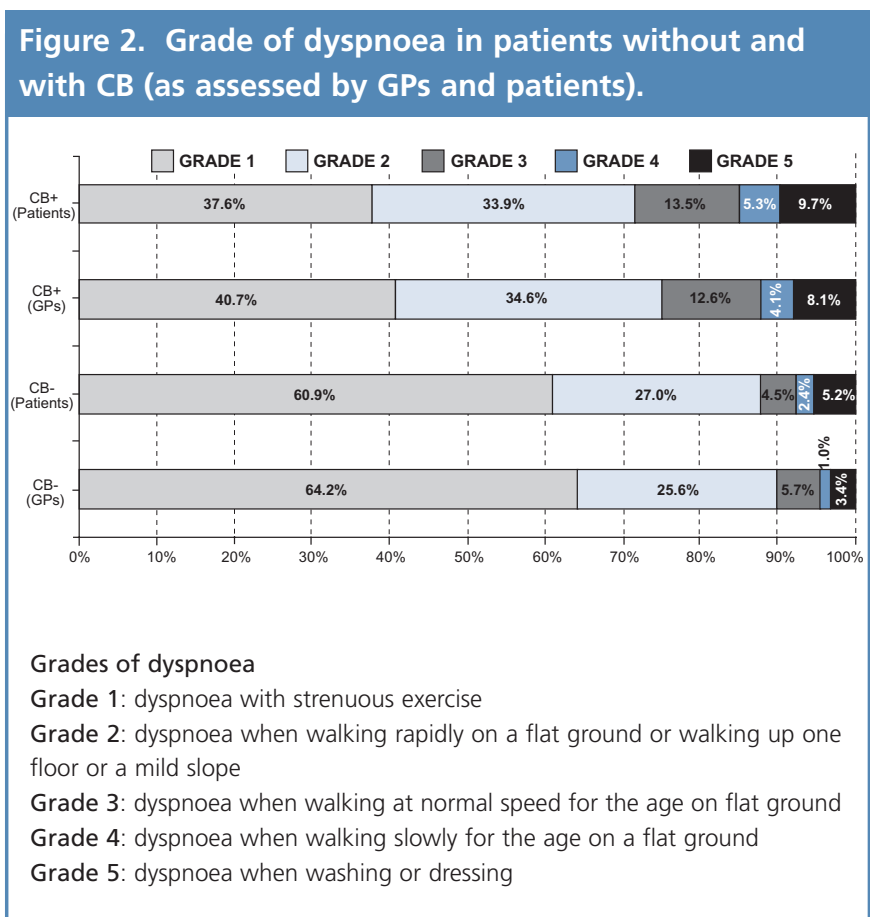

The prevalence of chronic bronchitis was 1.5 times higher in patients aged more than 55 years $(p=0.011), 2.2$ times higher in patients presenting more than two acute bronchitis episodes per year $(p=0.004)$, and consequently 2.3 times higher in patients having been treated by antibiotics more than twice during the past year $(p=0.009)$.

Impact of chronic bronchitis on patients' quality of life and activity

The global QoL, as assessed by the patients on the $100 \mathrm{~mm}$ visual analogue scale of the EuroQOL-5D questionnaire, was more altered in patients with chronic bronchitis: $58.4 \pm 17.5$ versus $68.9 \pm 17.7 \mathrm{~mm}(p<0.001)$. For each domain of the EuroQOL-5D questionnaire (mobility, autonomy, problems in daily activities, pain and discomfort, anxiety or depression), QoL was significantly impaired in patients with chronic bronchitis $(p<0.001)$ (see Figure 3 ).

Within the past three years, the proportion of patients having stopped their activities due to respiratory disorders was $62.2 \%$ in patients with chronic bronchitis compared to $22.6 \%$ of the patients without AECB $(p<0.001)$. Consequently, the time lost from work due to respiratory disorders was higher in patients with, than without, chronic bronchitis $(p<0.001)$ (see Figure 4). Altogether, chronic bronchitis was 3.7 times more frequent in patients with more than four weeks lost from work in the previous year due to respiratory disorders $(p<0.001)$.

Compared to patients with less than two weeks lost from work, patients who stopped working for two or more weeks within the past year presented with a lower global QoL
Figure 3. Patients' quality of life according to the absence or presence of CB.

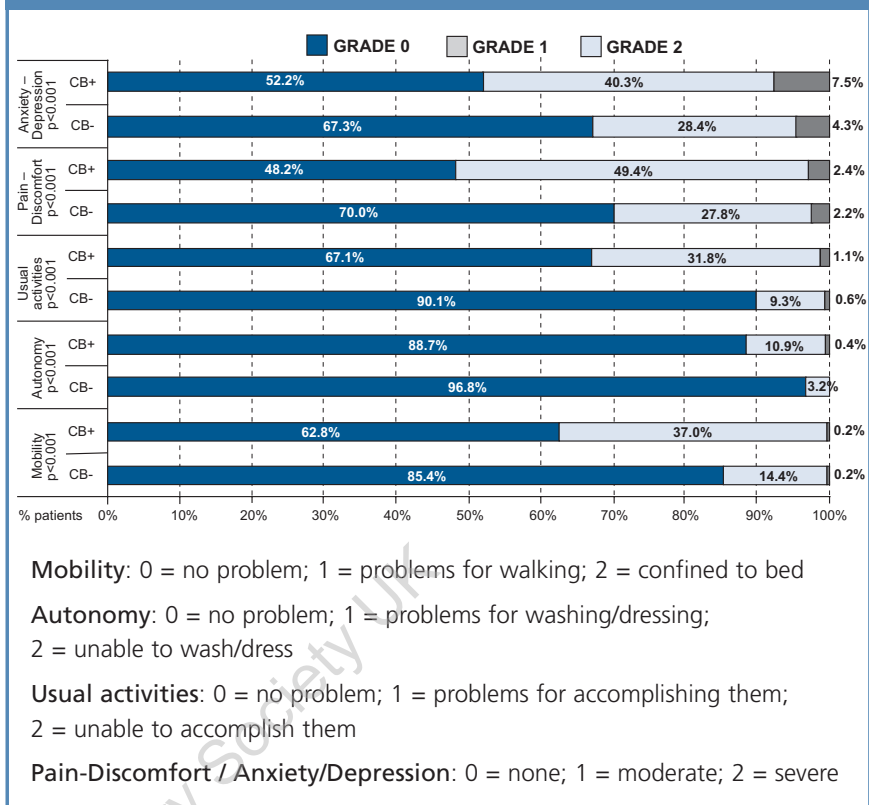

Figure 4. Time lost from work due to respiratory disorders within past year in patients with and without $\mathrm{CB}$.

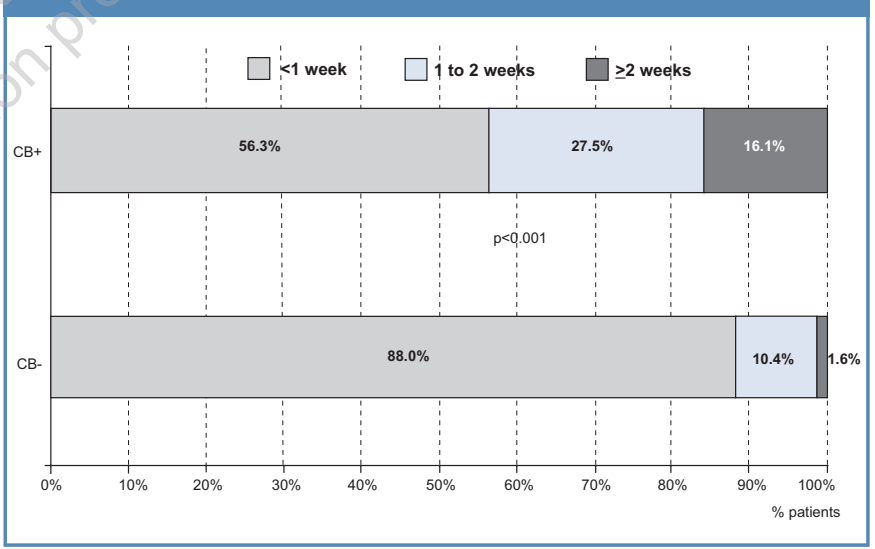

(respectively: $63.0 \pm 17.4$ vs $51.7 \pm 16.9-p<0.001$ ). They also reported more frequently an impairment in mobility (25.0\% vs $60.0 \%-p<0.001)$, autonomy $(6.2 \%$ vs $21.8 \%$ $\mathrm{p}<0.001)$ and ability to accomplish usual activities $(20.9 \%$ vs $51.3 \%-p<0.001)$. Pain or discomfort was also more frequent in these subjects $(41.3 \%$ vs $68.6 \%-p<0.001)$, as well as anxiety or depression ( $41.1 \%$ vs $60.6 \%-p<0.001)$.

Care-seeking and previous acute respiratory episodes The frequency of acute respiratory episodes and care-seeking in patients with or without chronic bronchitis are summarised in Table 2. The proportion of patients having already been consulted and consequently having received antibiotic treatments for acute bronchitis was higher among patients with underlying chronic bronchitis. 


\begin{tabular}{|c|c|c|c|}
\hline $\begin{array}{l}\text { Number of patients with } \\
\text { complete autoquestionnaire }\end{array}$ & $\begin{array}{l}\text { with CB } \\
\mathrm{n}=2,021\end{array}$ & $\begin{array}{l}\text { without CB } \\
\qquad \mathrm{n}=510\end{array}$ & $\mathrm{p}$ value \\
\hline \multicolumn{4}{|c|}{$\begin{array}{l}\text { Number of patients whose physician already spoke about } \\
\text { chronic bronchitis }\end{array}$} \\
\hline Patients quest. \% (n) & $74.6 \%(1,496)$ & $8.3 \%(42)$ & $<0.001$ \\
\hline \multicolumn{4}{|c|}{ Number of patients already followed up for chronic bronchitis } \\
\hline Patients quest. \% (n) & $45.5 \%(917)$ & $2.6 \%(13)$ & $<0.001$ \\
\hline \multicolumn{4}{|c|}{ Number of patients followed up for cardiovascular disease } \\
\hline Patients quest. \% (n) & $30.5 \%(613)$ & $20.3 \%(103)$ & $<0.001$ \\
\hline \multicolumn{4}{|c|}{ Number of acute bronchitis per year (GPs' questionnaire) } \\
\hline Mean \pm SD & $2.7 \pm 1.4$ & $1.5 \pm 0.9$ & $<0.001$ \\
\hline \multicolumn{4}{|c|}{ Patients having consulted for previous similar episodes } \\
\hline Patients quest. \% (n) & $88.8 \%(1,781)$ & $62.5 \%(317)$ & $<0.001$ \\
\hline \multicolumn{4}{|c|}{ Patients treated with antibiotics for similar episodes within past year } \\
\hline GPs quest. \% (n) & $96.4 \%(2,603)$ & $79.8 \%(544)$ & $<0.001$ \\
\hline Patients quest. \% (n) & $83.6 \%(1,546)$ & $60.3 \%(293)$ & $<0.001$ \\
\hline \multicolumn{4}{|c|}{ Number of antibiotic treatments within past year } \\
\hline & $12 \geq 2$ & $12 \geq 2$ & \\
\hline GPs quest. \% & 19.236 .141 .1 & 45.027 .17 .6 & $<0.001$ \\
\hline Patients quest. \% & 26.937 .036 .1 & 64.326 .49 .3 & $<0.001$ \\
\hline \multicolumn{4}{|c|}{$\begin{array}{l}\text { Patients having already consulted for the current episode } \\
\text { and received antibiotics }\end{array}$} \\
\hline GPs quest. \% (n) & $23.5 \%(629)$ & $11.1 \%(75)$ & $<0.001$ \\
\hline Antibiotics \% (n) & $81.0 \%(498)$ & $78.4 \%(58)$ & 0.593 \\
\hline Patien & $20.3 \%(408)$ & $9.9 \%(50)$ & $<0.001$ \\
\hline Antibiotics \% (n) & $79.8 \%(320)$ & $65.3 \%(32)$ & 0.020 \\
\hline
\end{tabular}

The planned management and treatments prescribed for the current episode in patients with or without chronic bronchitis are shown in Figure 5. The presence of acute bronchitis was associated with closer and more specialised follow-up, as well as with more frequent prescriptions of antibiotics, inhaled bronchodilators and oral corticosteroids, and less frequent use of anti-cough agents.

\section{Discussion}

In this study of 14,030 adult patients consulting a GP with a primary diagnosis of acute bronchitis, $43 \%$ were at risk of COPD (> 40 years of age and tobacco use $>10$ pack-years). Among these, $79.8 \%$ were diagnosed with underlying chronic bronchitis. Compared to patients without chronic bronchitis, they were older, had been or were more exposed to occupational or environmental pollutants, and had a longer history of tobacco use. They also more frequently reported dyspnoea of Grade 2 or more. Most importantly, their QoL was more altered and they reported more time lost from work due to respiratory disorders and more acute respiratory episodes and visits to physicians.

Some potential sources of bias may have influenced the results of this survey. The lack of exhaustive and consecutive enrolment could have led to a selection of patients presenting
Figure 5. Management planned and treatments prescribed for the acute respiratory episode in patients without and with $\mathrm{CB}$.

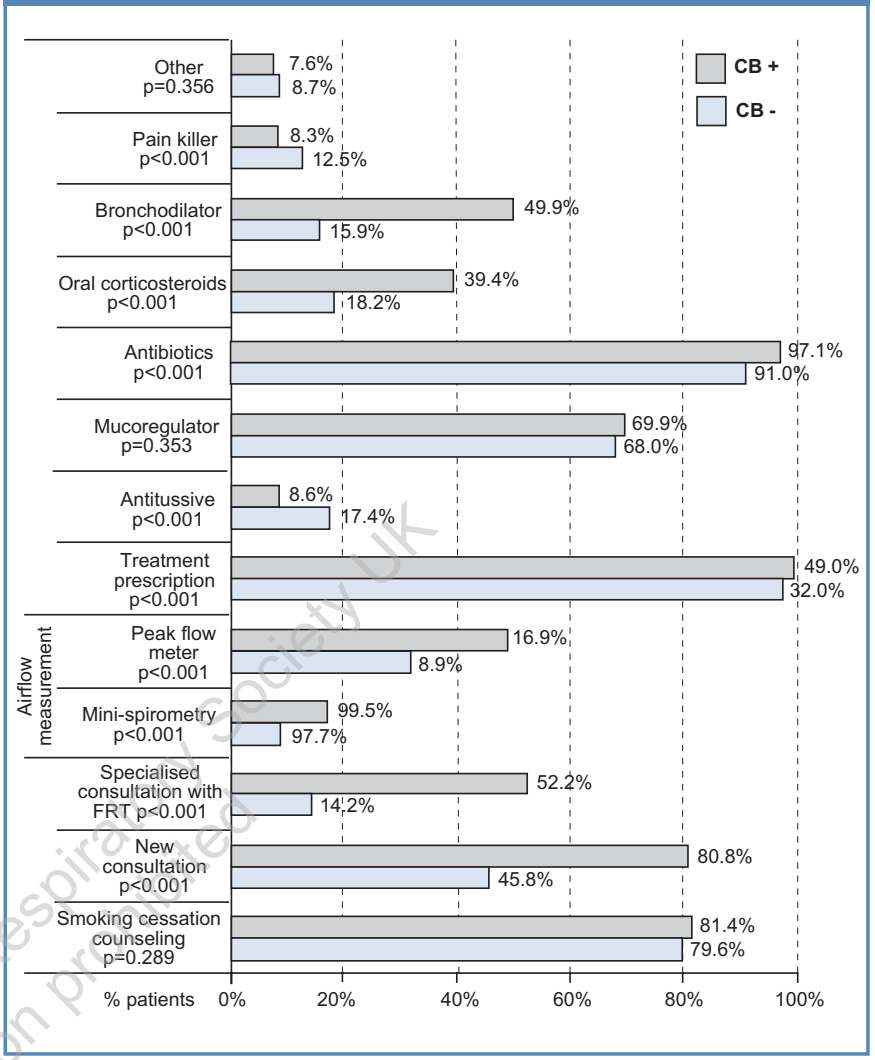

more risk factors and/or symptoms. Thus, we cannot draw any conclusion regarding the prevalence of risk factors and chronic bronchitis in the studied population, but this was not the main goal of the study.

The targeted size of the study population $(n=3,825)$ was not reached, but the actual number of subjects $(n=3,615)$ only marginally affected the power of the study (precision of the estimate: $2.1 \%$ vs $2.0 \%$ ).

Since spirometry was not performed, it is not possible to determine the frequency of underlying COPD in the studied population. Thus, we cannot distinguish between the impact of chronic sputum production and that of airflow obstruction. In any case, our results show that, in subjects with a clinical presentation and primary diagnosis of acute bronchitis, it is worth identifying those with risk factors for COPD and, among them, those with previously undiagnosed chronic bronchitis. In these subjects, poorer QoL, work loss and consumption of healthcare resources suggest ill health.

Some cases of acute episodes and symptoms of chronic bronchitis may be related to asthma in the studied population. However, subjects reporting that a doctor ever mentioned a diagnosis of asthma were excluded from the study. Other diseases such as bronchiectasis cannot be ruled out either, but 
they are far less frequent in the general population. In any case, the impairment in QoL and activity in subjects with symptoms of chronic bronchitis suggests that spirometry might be useful in these subjects, whichever underlying chronic respiratory disease is finally diagnosed.

The diagnosis of COPD is based on spirometry. Some studies have shown that systematic spirometry in smokers in general practice may permit detection of previously undiagnosed COPD in $10 \%-20 \%$ of screened subjects, a substantial proportion of them having moderate to severe disease. ${ }^{23}$ However, systematic screening of smokers who do not recognise or report symptoms has been discouraged by recent guidelines, ${ }^{24}$ which state that it would not be cost effective in terms of number-needed-to-screen to prevent one exacerbation. This position can be debated since it is not known whether early detection could delay handicap or death through the early implementation of appropriate treatment and advices.

Nevertheless, symptom-based case-finding by GPs may be more realistic, especially in settings such as France where spirometry is not performed in primary care. Simple patient selfadministered questionnaires have been developed in order to identify patients with a high likelihood of COPD, and for whom spirometry has to be performed..$^{16}$ The sensitivity of a COPD diagnostic questionnaire was found to be as high as $80 \%$ with a $70 \%$ specificity in its initial development study, making it potentially useful in routine primary care practice. Indeed, the use of this questionnaire was subsequently advocated in the guideline for Chronic Airways Diseases of the International Primary Care Airways Group. However, a study of its external validity recently provided rather disappointing results, with a high false-positive rate and low area under the ROC curve. ${ }^{25}$ Such results are likely to prevent this questionnaire from being generalised.

Our data suggest that acute respiratory episodes (which were not part of the above-mentioned questionnaire) could be a useful entry in the screening approach. The recurrence of such episodes should also be a trigger for screening, as shown by the higher number of acute respiratory episodes in subjects with chronic bronchitis. Spirometry-based studies are required to determine the proportion of COPD cases in at-risk subjects with chronic bronchitis detected using this approach. This proportion should be compared to that observed in at-risk patients without chronic bronchitis. This will allow one to determine the performance of screening for chronic bronchitis, as a tool to help detecting underlying COPD or other chronic respiratory diseases.

Interestingly, clinical practice appears to be modified when chronic bronchitis is discovered, with a higher rate of prescription of bronchodilators, oral corticosteroids and antibiotics. As shown in figure 5, more frequent and specialised follow-up is also planned in subjects with newly diagnosed chronic bronchitis. In the present study, we obviously have no way to determine whether these decisions lead to better outcomes. As mentioned above, this will require further prospective studies.

\section{Conclusion}

These survey results show a high prevalence of chronic bronchitis in at-risk patients visiting their GP for an acute bronchitis episode. Although no diagnosis of chronic respiratory disease had been made before in most patients, the burden of chronic bronchitis was high in terms of health status, consumption of healthcare resources and work loss. As patients tend to adapt to the insidious onset of COPD symptoms and seek medical advice only late in the course of the disease, acute respiratory episodes could be a useful opportunity for spirometry screening and initiating active COPD prevention and management.

\section{Conflict of interest}

This study was sponsored by Abbott France.

\section{References}

1. Murray CJ, Lopez AD. Alternative projections of mortality and disability by cause 1990-2020: global burden of disease study. Lancet 1997;349:1498-1504. http://dx.doi.org/10.1016/S0140-6736(96)07492-2

2. Fletcher CM, Peto R, Tinker CM, Spizer FE. The natural history of chronic bronchitis and emphysema. Oxford, Oxford University Press, 1976.

3. Pauwels RA, Buist AS, Calverley PM, Jenkins CR, Hurd SS. Global strategy for the diagnosis, management, and prevention of chronic obstructive pulmonary disease. NHLBI/WHO Global Initiative for Chronic Obstructive Lung Disease (GOLD) Workshop summary. Am J Respir Crit Care Med 2001;163:1256-76.

4. 15th Consensus Conference on anti-infective therapy held by the SPILF (the Frenchlanguage Society for Infectious Diseases): management of lower respiratory infections in the immunocompetent adult (a short text is available on the SPILF's web site: http://www.infectiologie.com/site/index.php)

5. Gorecka D, Bednarek M, Nowinski A, Puscinska E, Goljan-Geremek A, Zielinski J. Diagnosis of airflow limitation combined with smoking cessation advice increases stop-smoking rate. Chest 2003;123:1916-23. http://dx.doi.org/10.1378/ chest.123.6.1916

6. Parkes G, Greenhalgh T, Griffin M, Dent R. Effect on smoking quit rate of telling patients their lung age: the Step2quit randomised controlled trial. BMJ 2008; 336:598-600.

7. Roche N, Dalmay F, Perez T, et al. FEV1/FVC and FEV1 for the assessment of chronic airflow obstruction in prevalence studies: do prediction equations need revision? Respir Med 2008;102:1568-74. http://dx.doi.org/10.1016/j.rmed.2008.06.007

8. Mannino DM, Buist AS. Global burden of COPD: risk factors, prevalence, and future trends. Lancet 2007;370:765-73. http://dx.doi.org/10.1016/S01406736(07)61380-4

9. Lundback $B$, Lindberg $A$, Lindstrom $M$, et al. Not 15 but $50 \%$ of smokers develop COPD?--Report from the Obstructive Lung Disease in Northern Sweden Studies. Respir Med 2003;97:115-22. http://dx.doi.org/10.1053/rmed.2003.1446

10. Zielinski J, Bednarek M. Early detection of COPD in a high-risk population using spirometric screening. Chest 2001;119:731-36. http://dx.doi.org/10.1378/ chest.119.3.731

11. Société de Pneumologie de Langue Française. Recommandations pour la prise en charge de la bronchopneumopathie chronique obstructive. Rev Mal Respir 2003;20:294-329.

12. Antó JM, Vermeire P, Vestbo J, Sunyer J. Epidemiology of chronic obstructive pulmonary disease. Eur Respir J 2001;17:982-94.

13. Roche N, Dalmay F, Perez T, et al. Impact of chronic airflow obstruction in a working 
population. Eur Respir J 2008;31(6):1227-33. http://dx.doi.org/ 10.1183/09031936.00089607

14. Rennard S, Decramer M, Calverley PM, et al. Impact of COPD in North America and Europe in 2000: subjects' perspective of Confronting COPD International Survey. Eur Respir J 2002;20(4):799-805. http://dx.doi.org/10.1183/09031936.02.03242002

15. Huchon GJ, Vergnenegre A, Neukirch F, Brami G, Roche N, Preux PM. Chronic bronchitis among French adults: high prevalence and underdiagnosis. Eur Respir J 2002;20:806-12. http://dx.doi.org/10.1183/09031936.02.00042002

16. Price DB, Tinkelman DG, Halbert RJ, et al. Symptom-based questionnaire for identifying COPD in smokers. Respiration 2006;73:285-95. http://dx.doi.org/ 10.1159/000090142

17. Roche N, Housset B, Huchon G. [Should we screen for COPD in the population]. Rev Mal Respir 2008;25:787-90. http://dx.doi.org/10.1016/S0761-8425(08)74341-9

18. Ekberg-Aronsson M, Pehrsson K, Nilsson JA, Nilsson PM, Lofdahl CG. Mortality in GOLD stages of COPD and its dependence on symptoms of chronic bronchitis. Respir Res 2005;6:98. http://dx.doi.org/10.1186/1465-9921-6-98

19. Pelkonen $M$, Notkola IL, Nissinen A, Tukiainen $H$, Koskela $H$. Thirty-year cumulative incidence of chronic bronchitis and COPD in relation to 30-year pulmonary function and 40-year mortality: a follow-up in middle-aged rural men. Chest 2006;130:1129-37. http://dx.doi.org/10.1378/chest.130.4.1129
20. Rabe KF, Hurd S, Anzueto A, et al. Global Strategy for the Diagnosis, Management, and Prevention of COPD - 2006 Update. Am J Respir Crit Care Med 2007; 176:532-55. http://dx.doi.org/10.1164/rccm.200703-456SO

21. de Marco R, Accordini S, Cerveri I, et al. An international survey of chronic obstructive pulmonary disease in young adults according to GOLD stages. Thorax 2004;59:120-5. http://dx.doi.org/10.1136/thorax.2003.011163

22. Rutten-van Molken MP, Oostenbrink JB, Tashkin DP, Burkhart D, Monz BU. Does quality of life of COPD patients as measured by the generic EuroQol five-dimension questionnaire differentiate between COPD severity stages? Chest 2006;130 (4):1117-28. http://dx.doi.org/10.1378/chest.130.4.1117

23. Tinkelman DG, Price DB, Nordyke RJ, Halbert RJ. COPD screening efforts in primary care: what is the yield? Prim Care Resp J 2007;16(1):41-8. http://dx.doi.org/10.3132/pcrj.2007.00009

24. Lin K, Watkins B, Johnson T, Rodriguez JA, and Barton MB. Screening for chronic pulmonary disease using spirometry: summary of the evidence for the US Preventive Services Task Force. Ann Intern Med 2008;148:535-43.

25. Kotz D, Nelemans P, van Schayck CP, Wesseling GJ. External validation of a COPD diagnostic questionnaire. Eur Respir J 2008;31:298-303. http://dx.doi.org/ 10.1183/09031936.00074307

\section{Available online at http://www.thepcrj.org}

